\title{
TELECOMMUNICATIONS REGULATION: AN INTRODUCTION
}

\author{
Nicholas Economides
}

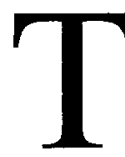

HE U.S. TELECOMMUNICATIONS sector is going through a significant change. A number of factors contribute and define this change. The first is the rapid technological change in key inputs of telecommunications and computer-based services and in complementary goods, which have dramatically reduced the costs of traditional telecommunications services and have made many new services available at reasonable prices. For example, telecommunications cost reductions have made access to the Internet affordable to the general public.

The second reason for the revolutionary change has been the sweeping digitization of the telecommunications and the related sectors. Not only has the underlying telecommunications technology become digital, but the consumer and business telecommunications interfaces have become more versatile and closer to multifunction computers than to traditional telephones. Digitization and integration of telecommunications services with computers create significant business opportunities, impose significant pressure on traditional pricing structures, especially in voice telephony, and threaten the fundamental features of the traditional regulatory regime.

The third reason for the current upheaval in the telecommunications sector was the passage of an important new law to govern telecommunications in the United States, the Telecommunications Act of 1996. Telecommunications has traditionally been subject to a complex federal and state regulatory structure. The 1996 act attempted to adapt the regulatory structure to technological reality, but various legal challenges by the incumbents have so far delayed, if not nullified, its impact.

In general, regulation should be used only when it is clear that deregulated markets are likely to fail even in the presence of reasonably strict antitrust enforcement. Clearly, the success or failure of a market in the absence of regulation depends crucially on the demand and cost conditions under the present 
technology. Progress and innovation in telecommunications technologies have been rapid for the past forty years and are expected to continue at a fast pace. As a result of technological change, cost conditions shift considerably over time and can transform a market that requires regulation into one that does not. This is crucial for telecommunications and has lead to progressive deregulation. For example, the market for long-distance telecommunications services, starting as a near monopoly in the mid-1970s, was formally completely deregulated in 1995, after strong competition in the 1980s and early 1990s emerged following the breakup of American Telegraph and Telephone (AT\&T) in 1984 and the opening of the long-distance market to competition. However, the process of deregulating some services while other services (often produced by the same firms) remain regulated is a complicated task with many pitfalls. Given the complex incentives of firms that participate in many markets and often face competitors who participate in just a few, it would be foolish to proceed with complete deregulation of the telecom sector without a careful analysis.

Telecommunications services are based on an increasingly sophisticated and complex network able to produce a rich variety of services that differ in distance traveled, quality, amount and nature of data or voice transmitted per unit of time, requirement of immediate (real-time) delivery, and so on. Making effective use of elements of market organization in many telecommunications contexts often requires considerable and detailed regulation. Many times, these regulations, even if they work well for existing markets, have pretty poor results when applied to markets for new products. This lack of flexibility of regulation is particularly important in modern telecommunications because new telecommunications services are continually produced, helped by the availability of complementary goods and services. For example, the demand for low-level data transmission as required by the World Wide Web and the Internet would not be possible without the wide availability and low prices of computers. But it would be foolish to start applying the traditional regulatory framework to the Internet, and the Federal Communications Commission (FCC) has correctly understood this.

Finally, telecommunications regulation is hampered by the various exigencies of regulation in general, such as political intervention and lobbying. Political intervention is complicated because some telecommunications services (such as access to emergency services) are essential for all and others, such as basic service, are considered necessities.

A number of factors drive the U.S. telecommunications industry today:

- dramatic and continuing reductions in the costs of transmission and switching

- digitization

- the 1984 breakup of AT\&T's monopoly, resulting in a competitive longdistance service sector and a monopolized local telecommunications sector 
- restructuring of the regulatory environment through the implementation of the 1996 Telecommunications Act, twelve years after the breakup of AT\&T

- the move of value from underlying services (such as transmission and switching) to interfaces and content

- the move toward multifunction programmable devices with programmable interfaces, such as computers, and away from single-function, nonprogrammable consumer devices, such as traditional telephone appliances

- reallocation of electromagnetic spectrum, allowing for expanded wireless services interconnection and interoperability of interconnected networks

- standardization of communications protocols

- the existence of network effects whereby connection to a large network is more valuable for each customer, and the fact that small networks unable to reach critical mass are unlikely to survive

These, in turn, have a number of consequences:

- increasing pressure for cost-based pricing of telecommunications services

- price arbitrage between services of the same time immediacy requirement

- increasing competition in long-distance services

- the possibility of competition in local services

- the emergence of Internet telephony (voice-over Internet protocol [VOIP]) as a major new telecommunications technology

\section{Why Have Telecommunications Regulation?}

To answer the question, "Why have telecommunications regulation?" one must first answer the question, "Why have regulation in general?" The logic of competition law in the United States is that efficiency (allocative, productive, and dynamic) is the desired outcome of antitrust policy, and competition is the means of achieving it. Thus antitrust laws are used to guard against restrictions on competition. Economic regulation has been established as a last resort for those markets where it is clear that competitive outcomes cannot be achieved by market forces; ${ }^{1}$ where deviation from economic efficiency is deemed socially desirable; where the social and private benefits are clearly different, including cases in which minimum safety standards increase social welfare; and to allow for coordination in technical standards or market equilibriums. ${ }^{2}$ Telecommunications can qualify under all four of these criteria as an industry in which some form of regulation is appropriate.

The main reason proposed for regulating telecommunications has been that a desirable competitive outcome could not be achieved by market forces. 
In the last decade of the nineteenth century and the first three decades of the twentieth century, AT\&T, after many of its patents had expired, faced significant competition in local telecommunications by independent telephone companies. The independents typically started at the local level and wired many businesses and households in small and midsize towns, sometimes also creating regional long-distance networks. There were periods in the first decade of the twentieth century when independents had in total more local lines than AT\&T, although the near monopoly of AT\&T in long distance was never seriously challenged until the 1970 s. AT\&T refused to interconnect with the independents, forcing many businesses to subscribe to two telephone companies with disconnected and incompatible networks, an independent to reach local customers (mainly households) and AT\&T to reach suppliers. ${ }^{3}$

AT\&T stated that it was concerned with the quality standards of independents and offered to incorporate most of them in the Bell System, but clearly there were also business and strategic reasons behind AT\&T's refusal to interconnect. The benefit to an independent telephone company of access to the AT\&T long-distance network was much larger than the benefit to AT\&T of adding to its network the mostly' residential customers of an independent. Although not clearly articulated in network economics terms, the issue facing the independents and AT\&T was clearly a fundamental issue in network economics. Modern network economics teaches us that the incentives of firms of different sizes to interconnect differ depending on the value and size of the new demand that is created by interconnection (Economides 1991; 1996). Typically, a large and high-value network has a significantly smaller incentive to interconnect with a smaller, low-value network than the smaller one has to interconnect with the larger one. This can easily lead to a refusal by the larger, high-value network to interconnect.

In summary, market incentives led AT\&T to refuse to interconnect with smaller (local and long-distance) networks, though such interconnection was considered socially desirable. This was the first reason for which regulation at the federal and state levels was imposed with a requirement to interconnect public switched telecommunications networks. ${ }^{4}$ There were clearly some service markets in the time period leading to the 1930s in which only one firm could survive. Monopoly prices in general are predicted to be high, and AT\&T's long-distance prices during this period were high. This gave a further justification to regulation, since free entry was unlikely to increase the number of competitors in many service markets.

The second and third reasons for regulation (deviation from social efficiency being desirable and a difference between the social and private value of telecommunications) were generally articulated after regulation was already in place. In the 1960s regulators did not let prices of basic local service rise in their attempt to achieve "universal service," that is, to include as many households as possible in the telecommunications network, on the basis that this 
was desirable even if it were allocatively inefficient. The ability of customers to receive calls and make emergency calls also played a role in setting the goal of universal service. Basic telecommunications service is now considered a necessity, and its inexpensive and ubiquitous provision is guaranteed by regulation. ${ }^{5}$

The fourth reason for regulation, that the regulator can help the industry achieve technical compatibility and avoid fragmentation, has had only limited application to telecommunications. Clearly, technical compatibility in a network industry is important since it allows all users to get the full benefits of the combined networks rather than the benefits of only the one they subscribe to. In practice, the present de facto compatibility standards in voice transmission and in higher data protocols are largely the legacy of the pre-1984 AT\&T monopoly and the adoption of Internet protocols that were created with government subsidization, with the requirement that they be made public. The regulatory requirements are typically on interconnection and at the level of voice transmission. There is no regulatory requirement of compatibility in many areas, including wireless equipment, wireless text messaging, higher data protocols, and interfaces. ${ }^{6}$

In understanding telecommunications regulation in the United States, it is useful to keep in mind the particular factors that made regulation the appropriate policy answer at some point in time. As technology and population densities change, some markets that may have been natural monopolies in the past may not be natural monopolies any more, and it may be better to allow competition in those markets while keeping regulation in the rest. The question of the desirability of regulation in various markets has been asked repeatedly over time, resulting in the present regime of progressive deregulation.

The public interest objective of telecommunications regulation is vague. Most economists agree that a valid objective is to increase total surplus, that is, consumers' surplus plus profits of active firms. Most economists also agree that the public interest should promote innovation and growth. Although it is difficult to quantify the exact effect of innovation and growth on income, there is wide consensus that these should be promoted and are part of the public interest. Finally, the public interest may include subsidization of telecommunications services that are considered necessities, such as basic local service, or those that are deemed to increase productivity and growth, such as Internet access. Given the vagueness of the concept of the public interest, various groups lobby politicians and regulators to include their objectives as part of the public interest. This rent-seeking behavior sometimes leads to telecommunications regulators to impose policies that have little to do with telecommunications markets.

Having outlined the potential benefits of regulation, I should also note that there are significant drawbacks and costs created by regulation. First, regulators generally do not have the latest technological information. In an industry with fast technological change, such as telecommunications, this can 
lead to significant divergence between costs and prices as costs fall much faster than prices. This has happened consistently both in the old regulated AT\&T and in regulated local-exchange carriers. Second, regulated firms may be able to use the regulatory setup to create barriers to entry and thereby perpetuate their profitable existence. For example, the first application of MCI to provide switched long-distance service was rejected by the FCC; MCI had to sue and was allowed in long-distance service only after a court decision. Third, the regulatory setup is slow, cumbersome, bureaucratic, and, in many cases, politically influenced. In practice, the regulatory system is much easier to influence by politicians than the judicial system. Fourth, because of the public interest provision, there can be significant rent-seeking activity by various groups, especially in issues relating to mergers that have strict, externally imposed deadlines. Fifth, in an industry with fast technical change, it is hard to define the appropriate array of regulated products; and new and evolving products are difficult to regulate correctly. Thus regulation should be used sparingly, and only when there are no good alternatives.

A new problem in regulatory supervision has been added with the recent aggressive intervention of the Competition Committee of the European Union in telecommunications matters. The European Union intervened in the mergers of MCI and WorldCom and of WorldCom with Sprint. This has created a situation in which large telecommunications companies contemplating a merger have to argue their case in front of the United States Department of Justice, the European Union Competition Committee, the public utilities commissions in fifty states, and other foreign regulatory bodies. This not only adds to the complexity and the cost of the merger but also creates the possibility that the requirements imposed by different regulatory bodies will contradict one another, and it would not be feasible to meet all of them. It also creates the possibility that conditions in financial markets may change considerably between the time a merger is announced and the time it is consummated, so that one of the merging parties may not find the merger desirable at the later date and may use a regulatory objection to abandon the merger without penalties. This increases the incentives of private parties opposing a merger to intervene, attempting to lengthen the approval process in hope that financial conditions may change during the approval process.

\section{U.S. Telecommunications Regulation}

Telecommunications has traditionally been a regulated sector of the U.S. economy. The market for telecommunication services and equipment went through various stages of competition after the invention of the telephone by Alexander Graham Bell. Regulation was imposed in the early part of this century and remains today in various parts of the sector. ${ }^{7}$ 


\section{The Period of AT\&T's Near Monopoly}

Following a period of expansion and consolidation, by the 1920s AT\&T had an overwhelming majority of telephony exchanges and submitted to state regulation. Federal regulation was instituted by the 1934 Telecommunications Act, which established the Federal Communications Commission. In its heyday, from the 1930s to 1981, AT\&T dominated all aspects of telecommunications in the United States. It had approximately 90 percent market share of local access lines and more than 90 percent of the long-distance revenue. It used almost exclusively equipment of Western Electric, its equipment division. It owned a top research laboratory, Bell Laboratories, which conducted both applied and theoretical research. Crucial scientific inventions of the twentieth century, such as the transistor and the integrated circuit, occurred at Bell Laboratories. By the 1970s, AT\&T had achieved universal service-more than 90 percent of U.S. households had a telephone-and it kept improving the quality of its services.

Regulation of the U.S. telecommunications market was marked by two important antitrust lawsuits that the U.S. Department of Justice brought against AT\&T and the Bell System. In the first one, United States v. Western Electric, filed in 1949, the U.S. Department of Justice claimed that the Bell operating companies practiced illegal exclusion by buying both production equipment and customer premises equipment (telephone appliances and switchboards) only from Western Electric, a part of the Bell System. The government sought a divestiture of Western Electric, but the case was settled in 1956, with AT\&T agreeing not to enter the computer market but retaining ownership of Western Electric. The second major antitrust suit, United States v. AT\&T, was started in 1974. The government alleged the following:

- that AT\&T's exclusive relationship with Western Electric was illegal

- that AT\&T monopolized the long-distance service market

- that AT\&T refused to interconnect telecommunications competitors as well as customers' premises equipment, thus being liable for a "refusal to deal"

- that AT\&T used various discriminatory practices that raised the costs of competitors

- that AT\&T abused the regulatory process and did not provide complete information to regulators

- that AT\&T set prices to exclude competitors, including practicing predatory pricing

The Department of Justice sought divestiture of both manufacturing and long-distance service from local service. ${ }^{8}$ Late in the Carter administration, 
the department offered to accept only the divestiture of manufacturing. AT\&T refused and later had to accept a much more onerous breakup. The case was settled by the modified final judgment in 1984. AT\&T retained its long-distance network, but seven regional Bell operating companies (RBOCs) were broken away from it. ${ }^{9}$ Each $\mathrm{RBOC}$ comprised a collection of local telephone companies that were part of the original AT\&T. Regional Bell operating companies remained regulated monopolies, each with an exclusive franchise in its region, and were not allowed to provide long-distance service.

Microwave transmission was a major breakthrough in long-distance transmission that created the possibility of competition in long distance. Microwave transmission was followed by technological breakthroughs in transmission through satellite and fiber-optic wire. By the time competition took root in long distance, fiber-optic technology had become the dominant technology of transmission.

\section{The Postbreakup Years}

The breakup of AT\&T crystallized the recognition that competition was possible in long distance while the local market remained a natural monopoly (see, for example, Crandall 1991). The biggest benefits to consumers during the past eighteen years have come from the long-distance market, which was transformed during this period from a monopoly to an effectively competitive market. However, consumers often do not reap the full benefits of cost reductions and competition because of an antiquated regulatory framework that, ironically, was supposed to protect consumers from monopolistic abuses and instead sometimes protects the monopolistic market structure.

Competition in long distance has been a great success. The market share (in minutes of use) of AT\&T fell from almost 85 percent in 1984 to barely 50 percent in 1998, as shown in figure 3.1, and presently below 45 percent. The revenue market share of AT\&T, shown in figure 3.2, also fell dramatically. Since the 1984 modified final judgment, the number of competitors in the long-distance market has increased dramatically. Soon after the judgment, two nationwide facilities-based competitors, MCI and Sprint, emerged as strong competitors of AT\&T. Facilities-based competitors deployed their own fiber-optic switched network. Over the past decade, a number of new strong facilities-based competitors entered with nationwide (or significant-coverage) networks, including Qwest, Level 3, Williams, and Global Crossing. ${ }^{10}$ There are also a number of smaller regional facilities-based carriers as well as a large number of "resellers" that buy wholesale service from the facilities-based long-distance carriers and sell to consumers. For example, there are currently about five hundred resellers competing in the California interexchange market, providing strong evidence for the ease of entry into this market. At least twenty new firms have entered the California market in each year since 1984. 
FIGURE 3.1 AT\&T's Market Share of Interstate Minutes, 1984 to 1998 , at Three-Month intervals

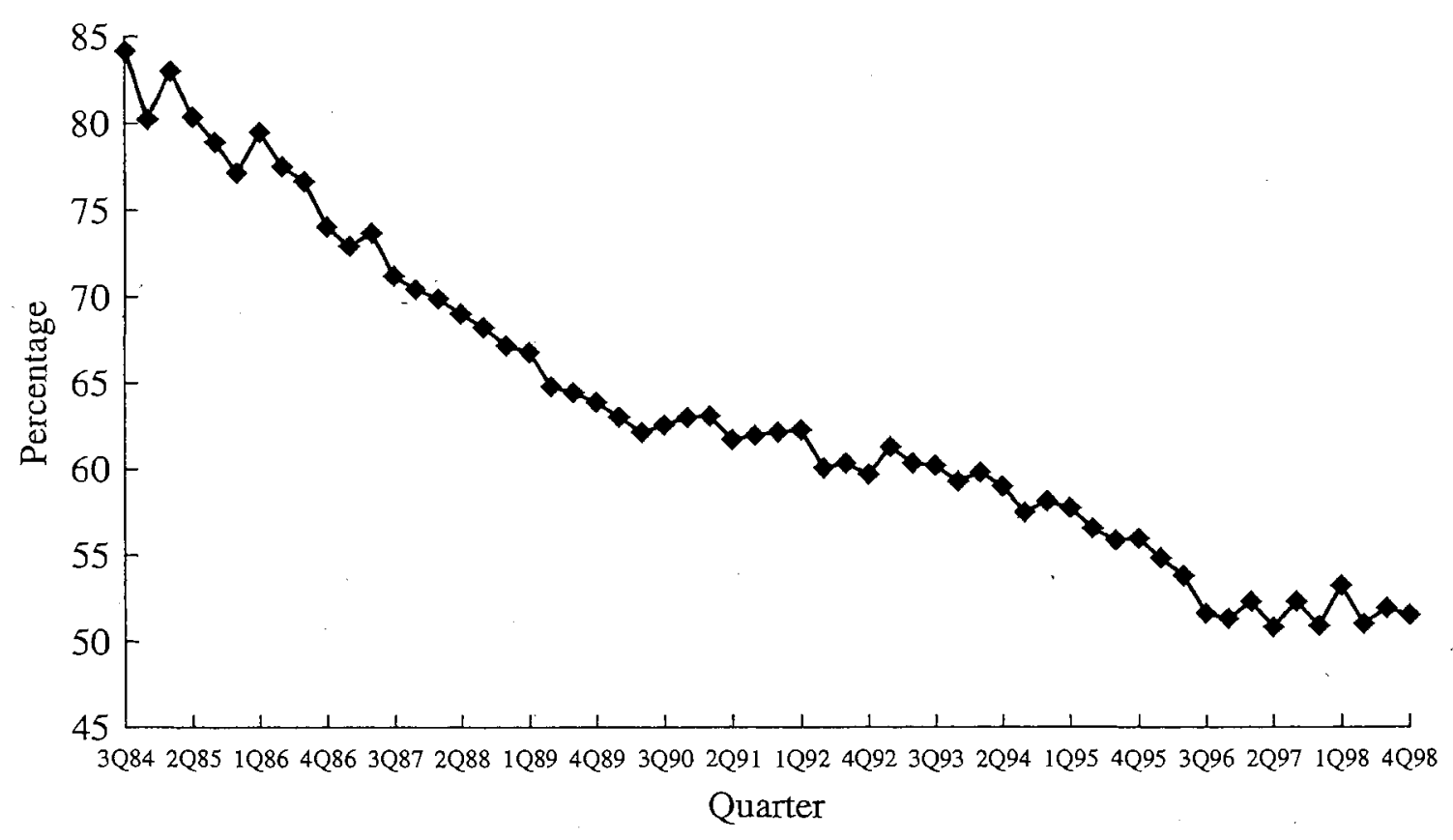

Source: Data from FCC (2003a; 2003c).

Prices of long-distance phone calls have decreased dramatically. The average revenue per minute of AT\&T's switched services was reduced by 62 percent between 1984 and 1996. Figure 3.3 shows the average revenue per minute for AT\&T relative to 1984 (upper line) as well as the average revenue per minute for AT\&T net of access charges relative to 1984 (lower line). ${ }^{11}$ The FCC declared AT\&T "nondominant" in the long-distance market in 1995 (FCC 1995). Most economists agree that presently the long-distance market is effectively competitive.

The modified final judgment did not allow the RBOCs to provide "inregion" long-distance phone service: that is, each RBOC was prohibited from offering long-distance service that originated in its local area. The main reasons for that restriction were to avoid three types of anticompetitive actions by a local service monopolist that would also own a long-distance service subsidiary: vertical price squeeze, price discrimination against the opponents of the local monopolist's long-distance subsidiary, and nonprice discrimination against the opponents of the local monopolist's long-distance subsidiary.

A long-distance phone call is carried by the local telephone companies of the place it originates and the place it terminates, and only in its long-distance part by a long-distance company. Originating access and terminating access 
FIGURE 3.2 AT\&T's Share of All Long-Distance Revenues, 1984 to 2001

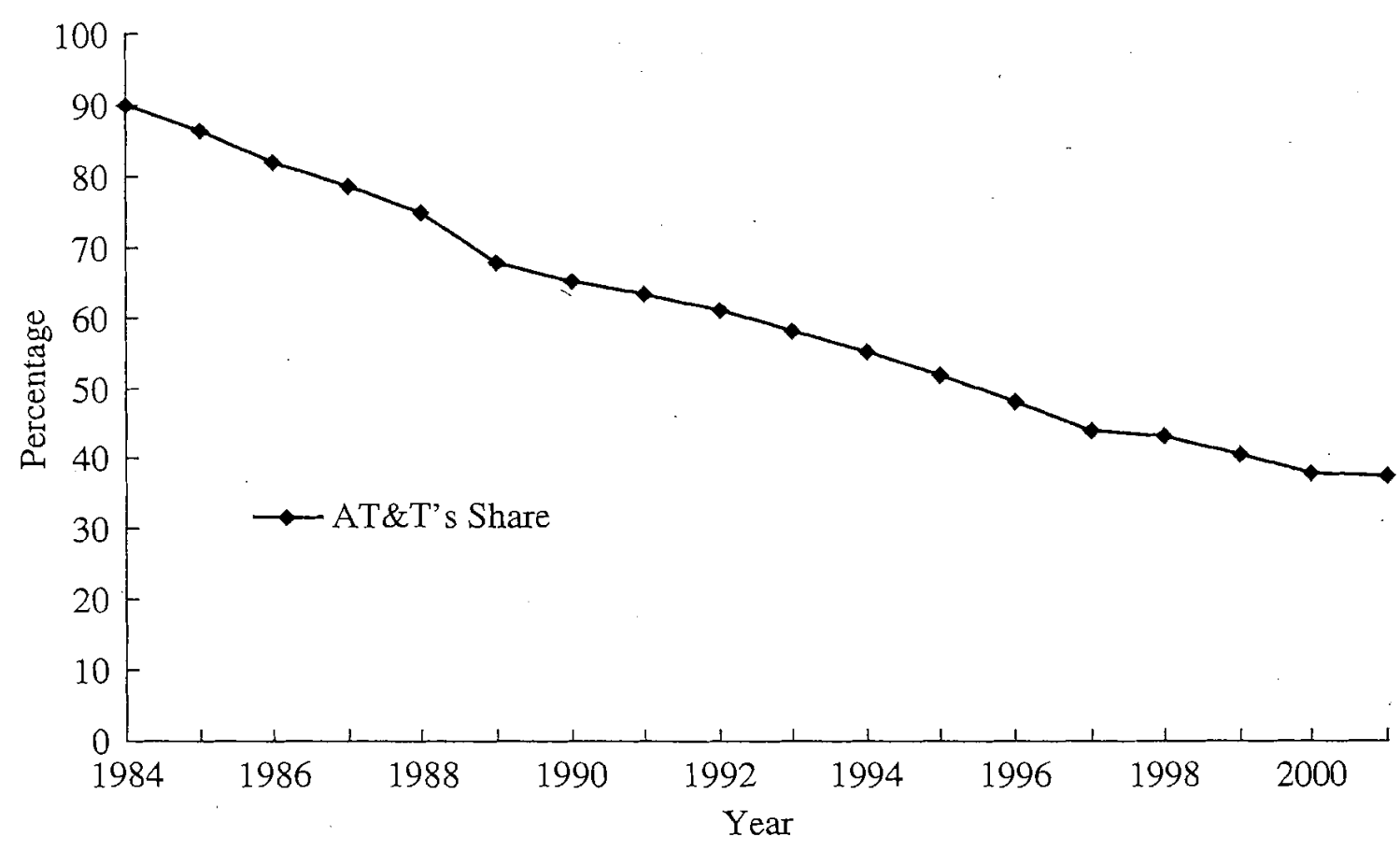

Source: Data from FCC (2003a; 2003c).

are provided by local-exchange carriers to long-distance companies and are essential bottleneck inputs for long-distance service. A local-exchange monopolist sets a per minute originating fee (a) paid by all long-distance companies for calls originating from its region. Origination and termination fees are approved by the state public utility commission. ${ }^{12}$ If the local-exchange monopolist also provides long-distance service, it can influence the maximum price per minute (p) that an independent long-distance company can charge. Thus a local-exchange monopolist that has vertically integrated in long-distance service can control the gross revenue per minute $(\mathrm{p}-\mathrm{a})$ of its long-distance rivals. By setting its long-distance price and influencing the access charge, the vertically integrated local-exchange monopolist can squeeze or even make negative the gross per minute revenue ( $\mathrm{p}-\mathrm{a}$ ) of the long-distance rivals so that they are marginalized or even driven out of business. This is called a "vertical price squeeze." A local-exchange monopolist with a long-distance subsidiary can also use price and nonprice discrimination against long-distance competitors to disadvantage them (see Economides 2003; Economides, Lopomo, and Woroch 1996; Economides and White 1995; Faulhaber 2004). Thus to insulate long-distance competition from leveraging in the long-distance market of the RBOC monopoly power in the local exchange and to protect the public 
FIGURE 3.3 Average Revenue per Minute (ARPM) of AT\&T's

Switched Services and ARPM Net of

Access Charges, 1984 to 1998

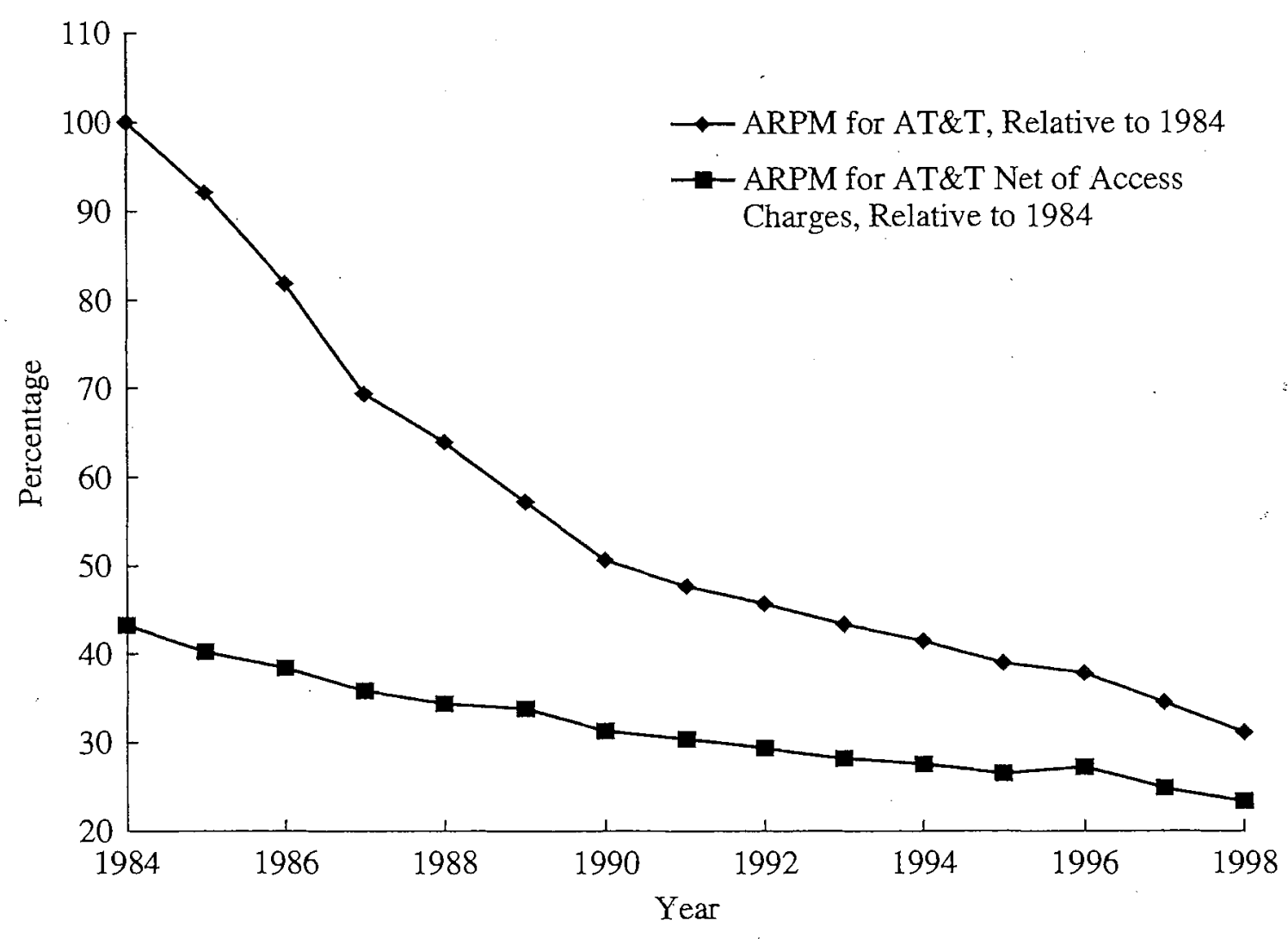

Source: Data from Hubbard and Lehr (1998).

interest, the 1984 modified final judgment restricted the RBOCs from providing in-region long-distance service. ${ }^{13}$

Local telephone companies that came out of the Bell System (RBOCs) actively petitioned the U.S. Congress to be allowed to enter the long-distance market. To a large extent in response to this pressure, Congress passed the Telecommunications Act of 1996. The great success of competition in long distance allowed Congress to appear balanced in the Telecommunications Act of 1996 by establishing competition in local telephony while allowing RBOCs into long distance after they had met certain conditions. However, the transition of local markets to effective competition will not be as easy or as quick as it was in the long-distance markets. This is because of the nature of the product and the associated economics.

Many telecommunications companies are presently trying to be in as many markets as possible so that they can bundle the various products. Com- 
panies believe that consumers are willing to pay more for bundled services for which the consumer receives a single bill. Bundling also discourages consumers from migrating to competitors, who may not offer the complete collection of services, so that consumer "churn" is reduced.

\section{The 1996 Telecommunications Act and Its Impact}

The Telecommunications Act of 1996 attempted a major restructuring of the U.S. telecommunications sector. The act will be judged favorably to the extent that it allows and facilitates the acquisition by consumers of the benefits of technological advances. Such a function requires the promotion of competition in all markets. This does not mean immediate and complete deregulation. Consumers must be protected from monopolistic abuses in some markets as long as such abuses are feasible under the current market structure, which was in many ways determined by the legacy of regulation. Moreover, the regulatory framework must safeguard against firms exporting their monopoly power in other markets.

In passing the Telecommunications Act of 1996, Congress took radical steps to restructure U.S. telecommunications markets. These steps had the potential to result in significant benefits to consumers of telecommunications services, telecommunications carriers, and telecommunications equipment manufacturers. But the degree of success of the act depends crucially on its implementation through decisions of the FCC and state public utility commissions and the outcome of the various court challenges that these decisions face.

The 1996 act envisioned a network of interconnected networks that are composed of complementary components and generally provide both competing and complementary services. The act used both structural and behavioral instruments to accomplish its goals. It attempted to reduce regulatory barriers to entry and competition. It outlawed artificial barriers to entry in local-exchange markets in an effort to accomplish the maximum possible competition. Moreover, it mandated interconnection of telecommunications networks, unbundling, nondiscrimination, and cost-based pricing of leased parts of the network, so that competitors can enter easily and compete component by component and service by service.

The act imposed conditions to ensure that de facto monopoly power would not be exported to vertically related markets. Thus it required that competition be established in local markets before the incumbent local-exchange carriers would be allowed in long distance. It preserved subsidized local service to achieve universal service but imposed the requirement that subsidization be transparent and that subsidies be raised in a competitively neutral manner. Thus it led the way to the elimination of subsidization of universal service through the traditional method of high access charges. 
It crystallized changes that had become necessary because of technological progress. Rapid technological change has always been the original cause of regulatory change. The radical transformation of the regulatory environment and market conditions that is presently taking place as a result of the 1996 act is no exception.

\section{Logic of the Act}

The logic behind the 1996 act was essentially to break the network into components and let everyone compete in every part, as well as in end-to-end services. To achieve this, the act mandates interconnection, unbundling, and nondiscrimination. Moreover, it takes away some of the incumbent's advantages that arise purely from historical reasons by mandating the lease of unbundled network elements at cost, mandating wholesale provision of any service presently provided by the incumbent local exchange carriers, and imposing phone number portability. To preserve the competition in long distance, the act attempted to ensure that monopoly power arising from historical or other reasons in the local exchange is not exported in other markets. Finally, it attempted to inpose nationwide standards for competition and take some regulatory power away from the states.

The 1996 Act allows entry of RBOCs in long distance after they open their local-exchange networks to competition. Thus from the point of view of an RBOC, entry into long-distance service provision was supposed to be the reward for allowing competition in the local exchange and losing its localexchange monopoly. The act was based on the belief that the individual private incentives of the RBOCs would be sufficient to drive the process. Thus it did not impose penalties for delay or noncompliance. This has proved to be a serious deficiency. Congress thought that the "carrot" of entry in long distance would be sufficient reward for RBOCs to open their local networks. Events have shown that Congress erred in this; RBOCs' behavior showed that they were willing to pay the price of staying out of long distance for a while rather than open their local networks.

\section{Entry in Local Services as Envisioned by the Act}

At the time of this writing, the "last mile" of the telecommunications network that is closest to the consumer (the "local loop") still remains a bottleneck controlled by a local-exchange carrier. The Telecommunications Act of 1996 boldly attempted to introduce competition into this last bottleneck, and, before competition took hold, to imitate competition in the local exchange.

To facilitate entry in the local exchange, the act introduced two novel ways of entry other than through the installation of owned facilities. The first 
allowed entry in the retailing part of the telecommunications business by requiring incumbent local-exchange carriers to sell to entrants at wholesale prices any retail service that they offer. Such entry is essentially limited to the retailing part of the market.

The second and most significant novel way was through the leasing of unbundled network elements from incumbents. In particular, the 1996 Act required that incumbent local-exchange carriers unbundle their networks and offer for lease to entrants network components (unbundled network elements) at prices "based on cost" (sect. 252[d][1][a][i]) that "may include a reasonable profit" (sect. 252[d][2]) and be "nondiscriminatory" (sect. 252[d][1][a][ii]). ${ }^{14}$ Thus it envisioned the telecommunications network as a decentralized network of interconnected networks. ${ }^{15}$

Many firms, including the large interexchange carriers AT\&T and MCIWorldCom, attempted to enter the market through "arbitration" agreements with incumbent local-exchange carriers under the supervision of state regulatory commissions, according to the procedure outlined by the act. The arbitration process proved to be extremely long and difficult, with continuous legal obstacles and appeals raised by the incumbent local-exchange carriers. To date, more than eight years after the signing of the act by President Bill Clinton, entry in the local exchange has been limited in most residential markets.

As of June 2003, entrant competitive local-exchange carriers provided service to 14.7 percent of the approximately 183 million local telephone lines nationwide (FCC 2003c, sec. 8, table 6), but only 3.4 percent of end users were served over facilities owned by competitive local-exchange carriers. ${ }^{16}$ Forty-two percent of all competitive local-exchange carriers' lines served medium and large business, institutional customers, and government customers. ${ }^{17}$ For services provided over leased facilities, the percentage of service by competitive local-exchange carriers, which is total service resale of services by incumbent local-exchange carriers, declined to 19 percent at the end of December 2002, while the percentage provisioned over acquired unbundled-network-element loops grew to 55 percent.

\section{Entry of RBOCs in Long-Distance Service}

In 1996 RBOCs had 89 percent of telephone access lines nationwide. Most of the remainder belonged to GTE and independent franchise holders. Competitive access providers (who did not hold a franchise monopoly) had less than 1 percent of all residential access lines nationwide. Besides providing access to longdistance companies, local-exchange carriers also provide lucrative custom local-exchange services such as call waiting, conference calling, and automatic number identification. Basic local service provided by local-exchange carriers is considered not to be particularly profitable. 
The act allowed for entry of RBOCs in long distance once a list of requirements had been met and the petitioner had proved that its proposal is in the public interest. These requirements are supposed to be met only when the market for local telecommunications services becomes sufficiently competitive. If the local market is not competitive when a monopolist incumbent local-exchange carrier enters into long distance, the local-exchange carrier can leverage its monopoly power to disadvantage its long-distance rivals by increasing their costs in various ways and by discriminating against them in its pricing. If the local market is not competitive when a monopolist incumbent local-exchange carrier enters into long distance, an incumbent local-exchange carrier (ILEC) controls the price of a required input (switched access) to longdistance service while competing for customers in long distance. Under these circumstances, an ILEC can implement a vertical price squeeze on its longdistance competitors whereby the price-to-cost ratio of long-distance competitors becomes so low that they are driven out of business. ${ }^{18}$

In allowing entry of local-exchange carriers into the long-distance market, the 1996 Telecommunications Act tried not to endanger competition that has developed in long distance by premature entry of RBOCs in the long-distance market. However, on this issue, the act's provisions guarding against premature entry may have been insufficient. Hence, to guard against anticompetitive consequences of premature entry of RBOCs in long distance there is need for a deeper analysis of the consequences of such entry on competition and on consumers' and social welfare. The FCC has not demanded significant competition before allowing RBOCs to enter long distance, and RBOCs are currently approved for long-distance service in all states. The history of the approval process is summarized in table 3.1 (see also FCC 2003b).

\section{Universal Service}

Traditionally, the United States has adopted a policy to maximize the subscribership of the public switched telecommunications network, commonly called universal service. Because universal service requires that some consümers be provided with basic telephone services below cost, from an efficiency standpoint there is overconsumption of those services. Most studies report very small price elasticities of demand for access, so the overconsumption effect may be small, and most of the distortion caused by universal service may be a wealth transfer effect. However, depending on how universal service is structured and provided, a host of other inefficiencies may also be created.

Historically, attaining the goal of universal service has focused on keeping basic rates for local-exchange telephone service low. To achieve this goal, the funds required to subsidize service were extracted from inter- and intra-LATA (local access transport area) long-distance service. Thus rates for carrier access 
TABLE 3.1 FCC Approval of Local-Exchange Carriers into the Long-Distance Market, 1997 to 2003

\begin{tabular}{|c|c|c|c|c|}
\hline State & Filed by & Status & Date Filed & Date Resolved \\
\hline Arizona. & Qwest & Approved & September 4, 2003 & December 3, 2003 \\
\hline $\begin{array}{l}\text { Illinois, Indiana, } \\
\text { Ohio, Wisconsin }\end{array}$ & $\mathrm{SBC}$ & Approved & July 17,2003 & October 15,2003 \\
\hline Michigan & $\mathrm{SBC}$ & Approved & June 19,2003 & $\begin{array}{l}\text { Due by } \\
\quad \text { September } 17,2003\end{array}$ \\
\hline Minnesota & Qwest & Approved & February 28, 2003 & June 26,2003 \\
\hline Michigan & $\mathrm{SBC}$ & Withdrawn & January 15,2003 & April 16, 2003 \\
\hline $\begin{array}{l}\text { New Mexico, } \\
\text { Oregon, } \\
\text { South Dakota }\end{array}$ & Qwest & Approved & January 15,2003 & April 15, 2003 \\
\hline Nevada & $\mathrm{SBC}$ & Approved & January 14, 2003 & April 14, 2003 \\
\hline $\begin{array}{l}\text { District of Columbia, } \\
\text { Maryland, } \\
\text { West Virginia }\end{array}$ & Verizon & Approved & December 18, 2002 & March 19, 2003 \\
\hline $\begin{array}{l}\text { Colorado, Idaho, } \\
\text { Iowa, Montana, } \\
\text { Nebraska, } \\
\text { North Dakota, } \\
\text { Utah, Washington, } \\
\text { Wyoming }\end{array}$ & Qwest & Approved & September 30, 2002 & December 23, 2002 \\
\hline California & $\mathrm{SBC}$ & Approved & September 20, 2002 & December 19, 2002 \\
\hline Florida, Tennessee & BellSouth & Approved & September 20, 2002 & December 19, 2002 \\
\hline Virginia & Verizon & Approved & August 1, 2002 & October 30,2002 \\
\hline $\begin{array}{l}\text { Montana, Utah, } \\
\text { Washington, } \\
\text { Wyoming }\end{array}$ & Qwest & Withdrawn & July 12,2002 & September 10, 2002 \\
\hline $\begin{array}{l}\text { New Hampshire, } \\
\text { Delaware }\end{array}$ & Verizon & Approved & June 27,2002 & September 25, 2002 \\
\hline $\begin{array}{l}\text { Alabama, Kentucky, } \\
\text { Mississippi, } \\
\text { North Carolina, } \\
\text { South Carolina }\end{array}$ & BellSouth & Approved & June 20,2002 & September 18,2002 \\
\hline $\begin{array}{l}\text { Colorado, Idaho, } \\
\text { Iowa, Nebraska, } \\
\text { North Dakota }\end{array}$ & Qwest & Withdrawn & June 13,2002 & September 10,2002 \\
\hline New Jersey & Verizon & Approved & March 26, 2002 & June 24,2002 \\
\hline Maine & Verizon & Approved & March 21, 2002 & June 19,2002 \\
\hline Georgia, Louisiana & BellSouth & Approved & February 14, 2002 & May 15, 2002 \\
\hline Vermont & Verizon & Approved & January 17, 2002 & April 17, 2002 \\
\hline New Jersey & Verizon & Withdrawn & December 20, 2001 & March 20, 2002 \\
\hline Rhode Island & Verizon & Approved & November 26, 2001 & February 24,2002 \\
\hline Georgia, Louisiana & BellSouth & Withdrawn & October 2, 2001 & December 20, 2001 \\
\hline Arkansas, Missouri & $\mathrm{SBC}$ & Approved & August 20, 2001 & November 16, 2001 \\
\hline Pennsylvania & Verizon & Approved & June 21,2001 & September 19,2001 \\
\hline Connecticut & Verizon & Approved & April 23, 2001 & July 20, 2001 \\
\hline
\end{tabular}

(Table continues on p. 64.) 
TABLE 3.1 Continued

\begin{tabular}{lllll}
\hline State & Filed by & \multicolumn{1}{c}{ Status } & \multicolumn{1}{c}{ Date Filed } & \multicolumn{1}{c}{ Date Resolved } \\
\hline Missouri & SBC & Withdrawn & April 4, 2001 & June 7, 2001 \\
Massachusetts & Verizon & Approved & January 16, 2001 & April 16, 2001 \\
Kansas, Oklahoma & SBC & Approved & October 26, 2000 & January 22, 2001 \\
Massachusetts & Verizon & Withdrawn & September 22, 2000 & December 18, 2000 \\
Texas & SBC & Approved & April 5, 2000 & June 30, 2000 \\
Texas & SBC & Withdrawn & January 10, 2000 & April 5, 2000 \\
New York & Verizon & Approved & September 29, 1999 & December 22, 1999 \\
Louisiana & BellSouth & Denied & July 9, 1998 & October 13, 1998 \\
Louisiana & BellSouth & Denied & November 6, 1997 & February 4, 1998 \\
South Carolina & BellSouth & Denied & September 30, 1997 & December 24, 1997 \\
Michigan & Ameritech & Denied & May 21, 1997 & August 19, 1997 \\
Oklahoma & SBC & Denied & April 11, 1997 & June 26, 1997 \\
Michigan & Ameritech & Withdrawn & January 2, 1997 & February 11, 1997 \\
\hline
\end{tabular}

Source: FCC (2003c).

and certain other services were set at artificially high levels to provide implicit subsidies to support the objective of universal service.

The historical method of promoting subscribership raised subsidies through taxing of traffic-sensitive services through the imposition of the federal, and in some cases state, common carrier line charges and was based on implicit and hidden subsidies. The historical method of raising subsidies for universal service compares poorly with the economically efficient method for a number of reasons. First, the historical subsidy is not explicit. Therefore, it is unclear who is subsidizing whom. For example, in the traditional regime, a rural customer who makes a significant number of toll calls in a high-cost area may not be subsidized in net terms. Second, the traditional mechanism is not targeted to those subscribers who require the subsidy. Instead, the local-exchange carrier receives the subsidy for serving all consumers regardless of their ability to pay the full cost, even if they live in an area where costs do not exceed revenues. Third, the burden of universal service is borne by inter- and intra-LATA toll users, rather than being funded broadly, thereby introducing inefficiencies in the provision of those services. Fourth, the traditional system is not competitively neutral because the benefits of the current system inure only to the incumbent localexchange carrier and not to any of their potential competitors. This system not only inhibits the introduction of competition in the local exchange (because the subsidies flow to the incumbent local-exchange carrier instead of to the carrier chosen by the consumer) but also may bestow unwarranted benefits on the incumbent local-exchange carrier to the extent the subsidies are inflated above amounts necessary to provide basic universal service at cost.

The 1996 act introduced fundamental changes in the structure of telecommunications markets in the United States. The most important thrust of 
the Telecommunications Act is its goal of establishing competition in all telecommunications markets. Competition generally drives prices closer to cost and imposes a strict discipline. As a result, and once competition takes hold, the prior implicit method of subsidization would no longer be viable. The act explicitly rejects such a process by requiring universal service support to be explicit (Telecommunications Act of 1996, sec. 254[e]) and by forbidding the continued use of universal service subsidies to cross-subsidize competitively provided services (sec. 254[k]).

The 1996 act aims to "preserve and advance universal service" (sec. $254[\mathrm{~b}])$. This translates to the following:

- high quality at low rates

- access to advanced services in all states

- access in rural and high cost areas at prices comparable to those in other areas

- service supported by "equitable and nondiscriminatory contributions" by "all providers of telecommunications services"

- specific and predictable mechanisms to raise the required funds

- access to advanced telecommunications services for schools, health care facilities, and libraries

Regulatory policy that explicitly deviates from the market outcome in the market for subscription creates a number of complex questions. Among them are who will be subsidized, by how much, by whom, and how the money will actually flow from the subsidizers to the subsidized. If these issues are not resolved in an efficient manner, economic distortions ("secondary distortions") may result that may be more significant than their original cause. For example, if the subsidy is extracted from subscribers of a single service, demand for that service will necessarily be impacted in ways that would not be consistent with the goals of the 1996 act. On the other hand, an efficient solution to these questions can guarantee that no further distortions are created by universal service, that is, no distortions over and above the original distortion created by the decision to maximize subscribership.

Funding for universal service should be achieved in a manner that is both efficient and competitively neutral. An economically efficient universal service fund should conform to the following criteria:

- All subsidies to promote universal service should be made explicit.

- Universal service should be funded broadly.

- Universal service subsidies should be targeted narrowly.

- Universal service should be achieved in a competitively neutral fashion. 
- The existence and operation of any universal service fund should minimize distortions to other telecommunications services.

- Subsidized consumers should be served in the most efficient way possible.

These characteristics are embodied in the 1996 Telecommunications Act. The act specifies that universal service subsidies should be made explicit (Telecommunications Act of 1996, sec. 254[e]), funded broadly (sec. 254[d]), and achieved in a competitively neutral fashion (sec. 254[b]). This framework minimizes to the maximum extent possible the problem of secondary distortions identified earlier in this chapter.

\section{The Failure of the 1996 Act and the Current Wave of Mergers}

Congress made a crucial miscalculation of the incentive of RBOCs to open their local networks to competition so that they would be rewarded with entry in long distance. In the summer of 1996, the RBOCs decided to delay entry of their local networks to competition as long as possible, even if that would lead to delay of their entry into the long-distance service market.

The various legal challenges have derailed the implementation process of the act and have increased uncertainty in the telecommunications sector. In the absence of reasonable final prices, given the uncertainty of the various legal proceedings, and without final resolution on the issues of nonrecurring costs and the electronic interface for switching local-service customers across carriers, entry in the local exchange through leasing of unbundled network elements has been slow. Moreover, entry in the retailing part of the business through total service resale has been minimal, since the wholesale discounts have been small.

In the absence of entry in the local exchange market as envisioned by the act, the major long-distance companies are buying other companies that give them some access to the local market. For example, MCI has merged with WorldCom, which had just merged with Brooks Fiber and MFS, which, in turn, also own some infrastructure in local-exchange markets. MCI-WorldCom has focused on the Internet, having acquired Internet backbone provider UUNET as part of MFS, and the business long-distance market. ${ }^{19}$ WorldCom proposed a merger with Sprint. The merger was stopped by both the U.S. Department of Justice and the Competition Committee of the European Union. The Department of Justice had reservations about potential dominance of the merged company in the market for global telecommunications services. The European Union had objections about potential dominance of the Internet backbone by the merged company. ${ }^{20}$ In June 2002 WorldCom filed for Chapter 11 bankruptcy protection after a series of revelations about accounting irregularities; as of this writing, the full effects of these events on the future of WorldCom 
and the entire industry are still open. MCI (WorldCom having reverted to its old name) has emerged from bankruptcy, and competitors are concerned that MCI will be a formidable competitor with no debts.

AT\&T acquired TCG, which owned local-exchange infrastructure that reached business customers. AT\&T unveiled an ambitious strategy of reaching consumers' homes by using cable television wires for the "last mile." With this end in mind, AT\&T bought TCI with the intent of converting the TCI cable access to an interactive broadband, voice, and data telephone link to residences. AT\&T had also entered in an agreement with Time Warner to use its cable connection in a way similar to TCI's, and in April 1999 AT\&T outbid Comcast and acquired MediaOne, the cable spin-off of U.S. West.

TCI cable at the time reached 35 percent of U.S. households. Together with Time Warner and MediaOne, AT\&T could reach a bit more than 50 percent of U.S. households. Without access to unbundled network elements to reach all residential customers, AT\&T had to find another way to reach the remaining U.S. households. The provision of telephony, Internet access, broadband, data, and two-way video services exclusively over cable lines in the "last mile" requires significant technical advances, significant conversion of the present cable networks, and an investment of at least $\$ 5$ billion (some say $\$ 30$ billion) just for the conversion of the cable network to two-way switched services. Moreover, there is some inherent uncertainty in such a conversion, which has not always been successful in the past. Thus it was an expensive and uncertain proposition for AT\&T, but, at the same time, it was one of the few remaining options of entry in the local exchange.

Facing tremendous pressure from financial markets, slow cable conversion, and a steep reduction in long-distance revenues, AT\&T decided on a voluntary breakup into a wireless unit, a cable TV unit, and a long-distance and local service company that retained the name AT\&T and the symbol " $T$ " on the New York Stock Exchange. Before the breakup, financial markets tended to underestimate the value of AT\&T by looking at it only as a long-distance company. After the breakup, the cable part of AT\&T was bought with by Comcast, and since then Comcast has generally not tried to attract new cable telephony customers using the AT\&T technology.

Attempts by the RBOCs to maximize their foothold, looking forward to the time when they would be allowed to provide long-distance service in all states, include Southwestern Bell's acquisition of Pacific Bell and Ameritech and Bell Atlantic's merger with NYNEX, despite some antitrust objections. Southwestern Bell also bought Southern New England Telephone, one of the few companies that, as an independent (not part of AT\&T at divestiture), was not bound by restrictions imposed under the modified final judgment and had already entered into long distance. Bell Atlantic has merged with GTE, creating Verizon. Thus the eight large local exchange carriers of 1984 (seven RBOCs and GTE) have been reduced to only four: Verizon, BellSouth, Southwestern 
Bell, and U.S. West. U.S. West recently merged with Qwest. The smallest one left, BellSouth, is widely reported to be a takeover or merger target.

A crucial crossmedia merger occurred with the acquisition of Time Warner by AOL at the height of AOL's stock price. The merger was achieved with the requirement that AOL/Time Warner allow independent Internet service providers access to its cable monopoly for broadband services. Synergies and new joint products failed to materialize at AOL/Time Warner. AOL has already been dropped from the trading symbol of the merged company, and there is wide speculation that AOL will be divested.

\section{The Telecom Meltdown of 2000 to 2003}

The present crisis in telecommunications arose out of an incorrect prediction of the speed of expansion of the Internet and therefore of the demand for all the new markets "living" on the Internet. It was widely believed that the Internet would grow at 400 percent in terms of transmitted bits per year. In retrospect, it is clear that for the years 2000 and 2001 growth of only 100 percent was realized. Of course, it is always difficult to pin down the growth rate in early stages of an exponential network expansion, and the Internet was growing at 400 percent a year when the original predictions were made. The rate of growth slowed down in the number of new hosts connected, however, and since no new "killer application" that required a lot of bandwidth was unveiled, the rate of growth in bits transferred also slowed down. This is despite the fast growth of transfers of bits in peer-to-peer (P2P) transfers of files among computers, mainly songs in MP3 format, popularized by Napster and still going strong even after Napster has been practically closed down. ${ }^{21}$

Based on the optimistic prediction of Internet growth, there was tremendous investment in Internet transport and routing capacity. Moreover, because capital markets were liberal in providing funds, a number of companies invested in and deployed more telecommunications equipment than would be prudent, given their present market share. This was done for strategic reasons, essentially in an attempt to gain market share in the process of the rapid expansion of the Internet.

Once the growth prediction was revised downward, the immediate effect was a significant reduction in orders and in investment in fiber-optic, switching, and router equipment. Before making significant new investments, telecommunications service companies are waiting for higher utilization rates of their existing capacity as the Internet expands. There is presently a temporary but significant overcapacity of Internet transmission capacity in the United States. As mentioned earlier, since it is easy to run the Internet backbone as a long-distance network, the significant overcapacity of the Internet backbone, combined with new investment and overcapacity of traditional long- 
distance networks, has led to significant pressure and reductions of longdistance prices. Thus the incorrect prediction of the Internet expansion has had negative repercussions not only in Internet-based business but also in the longdistance business and in the market for telecommunications equipment.

\section{Internet Telephony and Regulatory Breakdown}

The Telecommunications Act of 1996 did not legislate any framework for the most revolutionary of all current innovations in telecommunications, Internet telephony, or more precisely Internet protocol-based telephony, more generally known as "voice-over IP." This is despite the emergence of IP (internet protocol) telephony as the favorite mode of operation of new telecommunications networks, such as those built by Qwest and Level 3, as well as the required conversion of traditional telecommunications networks, such as AT\&T's.

Digitization of telecommunication services imposes price arbitrage on the bits of information that are carried by the telecommunications network, leading to the elimination of price discrimination between voice and data services. Elimination of such price discrimination can, in turn, lead to dramatic reductions in the price of voice calls, precipitating significant changes in market structure. These changes were first evident on the Internet, a ubiquitous network of applications based on the transmission control and Internet protocols (TCP/IP). Internet-based telecommunications are based on packet switching. There are two modes of operation: a time-delay mode, in which there is a guarantee that the system will do whatever it can to deliver all packets, and a real-time mode, in which packets can be lost without possibility of recovery.

Many telecommunications services do not have a real-time requirement, so applications that "live" on the Internet can easily accommodate them. For example, a number of companies currently provide facsimile services on the Internet, all or part of the transport of the fax taking place over the Internet. Although the Internet was not intended to be used in real-time telecommunications, despite the loss of packets telecommunications companies presently use the Internet to complete ordinary voice telephone calls. Voice telecommunications service started on the Internet as computer-to-computer calls. In 1995 Internet telecommunications companies started offering termination of calls on the public switched network. In 1996 firms started offering Internet calling that originated and terminated on the public switched telecommunications network ("PSTN"), that is, from and to the regular customers' phone appliances. The last two transitions became possible with the introduction of PSTN-Internet interfaces and switches by Lucent and others.

Traditional telephony keeps a channel of fixed bandwidth open for the duration of a call. Internet calls are packet based. Because transmission is based on packet transport, IP telephony can utilize bandwidth more efficiently 
by varying in real time the amount of it used by a call. But because IP telephony utilizes Internet real-time mode, there is no guarantee that all the packets of a voice transmission will arrive at the destination.

Internet telephony providers use sophisticated voice sampling methods to decompose and reconstitute voice so that packet losses do not make a significant audible difference. Since such methods are by their nature imperfect, the quality and fidelity of an Internet call depends crucially on the percentage of packets that are lost in transmission and transport.

This, in turn, depends on other factors, including the allocation of Internet bandwidth (pipeline) to the phone call, the number of times the message is transmitted, and the number ("hops") of routers over which the phone call passes. Internet-based telecommunications services pose a serious threat to traditional telecommunications service providers, including long-distance service, international service, and local service providers. In the present U.S. regulatory structure, a call to an Internet service provider that originates from a computer (or terminates to a computer) is not charged an access charge by the local-exchange carrier. This can lead to substantial savings owing to the inflated access fees charged by-local-exchange carriers.

Computer-to-computer Internet telephony has been available since 1998 but has not been widely used except for international calls, especially in countries where international rates are astronomical (see Garcia-Murillo 2003). However, a number of competitors, including AT\&T, have recently entered the voice-over IP telephony market, attempting to substitute traditional local telephone service with IP telephony over a cable television or digital subscriber line (DSL) Internet connection. These companies provide appliances that look and feel like traditional phones and, because they deliver all calls over the Internet, have low prices.

In summary, although the Internet was not created for real-time interaction, its user datagram protocol (UDP) mode has been used for voice telecommunications (Internet telephony). Internet telephony will mature as the quality of routers and the meshing of the IP database with the U.S. phone-numbering system improve. As Internet telephony improves in quality and Internet phone calls become widely available, artificially high prices of voice calls will not be sustainable because of arbitrage in the bits. This will cause a major problem of regulatory breakdown in which it is likely that major telecommunications companies will ask for regulation of the Internet so that voice-call prices do not collapse.

\section{The Coming World}

The intent of the Telecommunications Act of 1996 was to promote competition and the public interest. It will be a significant failure of the U.S. political, legal, and regulatory systems if the interests of entrenched monopolists, rather 
than the public interest as expressed by Congress, dictate the future of the U.S. telecommunications sector. The market structure in the telecommunications sector two years from now will depend crucially on the resolution of the localexchange carriers' legal challenges to the 1996 Telecommunications Act and its final implementation. ${ }^{22}$ At the time of this writing (June 2004), the prospects for competition in the local exchange in the manner anticipated by the 1996 act are bleak. The Appeals Court in Washington, D.C., has thrown out substantial parts of the triennial review order of the FCC (United States Telecom Association v. FCC, no. 00-1012, decided March 2, 2004), which defined a framework for continuing leasing of unbundled network elements by RBOCs. The solicitor general and the FCC decided not to appeal this decision to the Supreme Court. The Supreme Court did not intervene, and now cost-based leasing of unbundled network elements is likely to be quickly phased out, and the RBOCs will be allowed to charge monopoly prices for unbundled network elements, resulting in a classic vertical price squeeze of entrants in the local exchange who lease unbundled network elements. Facing an imminent vertical price squeeze by the RBOCs and the increasing sale of "buckets" of combined local and long-distance minutes, which it would not be able to match in the vertical price squeeze situation, on July 22, 2004, AT\&T decided to stop marketing both local and long-distance services to residential customers. Thus the 1996 act's vision of competition in the local exchange through leasing of unbundled network elements essentially is dead. As wireless service is still not of the same quality as traditional fixed service, the only significant challenge to the RBOCs' dominant (and, in many states, near monopoly) position in the residential and small-business market is voice-over IP, and there is much uncertainty over the viability of competition based on voice-over IP.

AT\&T's decision to stop marketing long distance to residential customers because of the leveraging of the RBOCs' dominance of the local market is exactly the type of undesirable event that was not supposed to happen as a consequence of allowing RBOCs to compete in the long-distance market. Thus the Telecommunications Act of 1996 has failed in its fundamental goals. First, competition in local markets through leasing of incumbents' networks did not materialize to a sufficient extent before it was abruptly killed by regulatory action. Second, the premature entry of RBOCs in long distance allowed them to implement a vertical price squeeze on local entrants, driving the largest one, AT\&T, out of the local market. Third, the liberalization of regulatory pricing rules on RBOCs allowed them to sell buckets of combined minutes of local and long-distance service, thereby implementing a vertical price squeeze with such force that even marketing stand-alone long distance to residential customers became unprofitable for the largest provider of residential longdistance services, AT\&T. The failure of the goals of the 1996 act is immense. Residential and small-business customers are likely to be significantly harmed by this enormous regulatory failure to protect them from monopoly. 
Already, we have seen a series of mergers leading to the remonopolization of local telecommunications. As the combinations of former RBOCs have been approved for long distance in all states, we see a reconstitution of the old AT\&T monopoly (without the present AT\&T). We have also seen significant integration in the cable industry as a result of the acquisitions and eventual divestitures of cable companies by AT\&T.

The local telephone companies have already entered the long-distance market without earlier significant decreases of their market shares in local markets. Local telephone companies have merged to expand their customer base and become stronger competitors in the next battle among carriers that sell both local and long-distance services. Twenty years after the government broke up the longstanding Ma Bell monopoly, the remonopolization of telecommunications is almost here.

Computers are likely to play a bigger role as telephone appliances and in running intermediate-size networks that will compete with local-exchange carriers and intensify the arbitrage among interexchange carriers. Computerbased telephone interfaces will become the norm. Firms that have significant market share in computer interfaces and computer operating systems, such as Microsoft, may play a significant role in telephony. ${ }^{23}$ Hardware manufacturers, especially firms like Cisco, Intel, and 3Com, that make switches and local networks will play a much more central role in telephony. Internet telephony (voice, data, and broadband) is expected to grow fast.

Finally, I expect that, slowly but steadily, telecommunications will drift away from the technical standards of the signaling-system seven established by AT\&T before its breakup. As different methods of transmission and switching gain a foothold, and as new interfaces become available, wars over technical standards are likely. ${ }^{24}$ This will further transform telecommunications from the traditional quiet landscape of regulated utilities to the mad-dash world of software and computer manufacturing. This change will create significant business opportunities for entrants and impose significant challenges on traditional telecommunications carriers.

\section{Notes}

1. For example, if the production technology has such high fixed costs that it is clear that only one firm will survive in the marketplace, resulting in a natural monopoly, regulation can be used to stop the monopolist from charging the high monopoly price.

2. Often, market interactions that can be modeled as economic games have multiple equilibriums, where each equilibrium is defined by a number of firms or individuals taking the same or similar actions. Then intervention by a regulatory body can coordinate the actions of firms or individuals, resulting in a more ben- 
eficial outcome. For example, cars can be driven on the left or the right side of the street, and, in principle, there is no particular advantage to an equilibrium in which all cars are on the left or all cars are on the right; but there are considerable disadvantages if some cars go on the right and some go on the left. Thus a regulatory body can create substantial benefits by imposing a rule whereby one of the two equilibriums is chosen.

3. See David Gabel and David F. Weiman (1998) and Weiman and Richard C. Levin (1994). Occasionally, AT\&T allowed interconnection to some independent local monopolists under the guarantee that these would not interconnect with any non-AT\&T exchange.

4. However, it should be noted that the requirement to interconnect could also have been imposed by antitrust authorities since the no-interconnection policy of AT\&T was equivalent to a "refusal to deal" and thereby broke antitrust law.

5. Still, there is no convincing evidence that the price for basic service is below cost, except possibly for some rural households. Moreover, adding households to the telecommunications network, even at a subsidized rate, may be desirable because of the network effects they produce to the rest of the consumers. Thus it is unclear that the provision of universal service has produced a considerable allocative efficiency distortion-if any.

6. Even when the FCC was auctioning spectrum and approving licenses for personal communication services (PCS) wireless services, it did not impose the same technical standard for wireless transmission; the result is three incompatible networks in the United States, in contrast to the single-standard global system for mobile communication (GSM) network in Europe.

7. The telecommunications sector is regulated both by the federal government, through the FCC, and by all states, typically through a public utilities commission or a public service commission. Usually a public utility commission also regulates electricity.

8. For a detailed exposition of the issues in this case, see Roger G. Noll and Bruce Owen (1989).

9. These were Ameritech, Bell Atlantic, BellSouth, NYNEX, Pacific Bell, Southwestern Bell, and U.S. West.

10. MCI merged with WorldCom, which had earlier expanded its original LDDS network and had acquired the Internet backbone of UUNET.

11. This is on a relative scale over time, since the carriers do not disclose actual price-to-cost margins.

12. Origination and termination of calls are extremely lucrative services. Access has an average cost (in most locations) of $\$ 0.002$ per minute. Its regulated prices vary. The national average in 2001 was $\$ 0.0169$ per minute. Such pricing implies a profit rate of 745 percent. Access charges reform is one of the key demands of the procompetitive forces in the current deregulation process.

13. However, non-RBOC local-exchange monopolists, such as GTE, had been traditionally allowed to provide long-distance service and were not restricted by the modified final judgment.

14. In FCC.(1996), the FCC and state regulatory commissions have interpreted these words to mean total element long-run incremental cost, which is the forwardlooking, long-run (minimized) economic cost of an unbundled element and in- 
cludes the competitive return on capital (see Gregg 2001 for a recent survey of UNE prices).

15. The implementation of the 1996 act started with the FCC's 'First Report and Order" (see FCC 1996).

16. The nationwide percentage of end-user lines served over facilities owned by competitive local-exchange carriers ( 3.4 percent) is derived by dividing the number of lines owned by competitive local-exchange carriers nationwide (FCC 2003a, table 10) by the total number of lines nationwide (FCC 2003a, table 6).

17. In contrast, 22 percent of reported incumbent local-exchange carriers' switched access lines served such customers.

18. Avoiding a vertical price squeeze of long-distance competitors, such as MCI, was a key rationale for the 1981 breakup of AT\&T in the long-distance division that kept the AT\&T name and the seven RBOCs that remained local monopolists in local service, as discussed earlier in this chapter. Also see Nicholas Economides (1998; 1999).

19. The MCI-WorldCom merger was challenged by the European Union Competition Committee, the Department of Justice, and GTE on the grounds that the merged company would have a large market share of the Internet backbone and could sequentially target, degrade interconnection, and kill its backbone rivals. Despite a lack of an economically meaningful definition of the Internet "backbone," the unlikelihood that MCI would have such an incentive because any degradation would also hurt its customers, and the unlikelihood that such degradation would be feasible, the Competition Committee of the European Union ordered MCI to divest itself of all its Internet business, including its retail business, where it was never alleged that the merging companies had any monopoly power. MCI's Internet business was sold to Cable and Wireless, the MCIWorldCom merger was finalized, and MCI-WorldCom is using its UUNET subsidiary to spearhead its way in the Internet.

20. The merged company proposed to divest Sprint's backbone. The European Union's objections were based on WorldCom's market share of about 35 percent in the Internet backbone market. The European Union used a peculiar theory predicting that "tipping" and dominance to monopoly would occur starting from this market share because WorldCom would introduce incompatibilities into Internet transmission and drive all competitors out of the market. Time proved that none of these concerns were credible.

21. Clearly, the Internet provides a superior wáy of distribution of music in digitized form. However, because of concerns that the music will be freely downloaded, the recording industry has avoided using this distribution process and is currently suing hundreds of individuals for allowing digitized music to be downloaded from their computers. Distribution of music and video in digitized form could significantly increase the amount of bits traveling on the Internet, but the present copyright dispute makes it unlikely that this will happen any time soon.

22. In one of the major challenges, GTE and a number of RBOCs appealed the 1996 FCC rules (among others) on pricing guidelines to the Eighth Circuit. The plaintiffs won the appeal; the FCC appealed to the Supreme Court, which ruled on January 25, 1999. The plaintiffs claimed (among other things) that the FCC's rules on the definition of unbundled network elements were flawed; that the FCC 
"default prices" for leasing of unbundled network elements were so low that they amounted to confiscation of incumbent local-exchange carriers' property; and that the FCC's "pick and choose" rule, allowing a carrier to demand access to any individual interconnection, service, or network element arrangement on the same terms and conditions the local-exchange carrier has given anyone else in an approved local competition entry agreement without having to accept the agreement's other provisions, would deter the "voluntarily negotiated agreements." The Supreme Court ruled for the FCC in all these points, thereby eliminating a major challenge to the implementation of the act.

23. Microsoft owns a share of WebTV, has invested in Qwest and AT\&T, and has broadband agreements with a number of domestic and foreign local-exchange carriers but does not seem to plan to control a telecommunications company.

24. A significant failure of the FCC has been its silence in defining technical standards and promoting compatibility. Even when the FCC had a unique opportunity to define such standards in PCS telephony (since it could define the terms while it auctioned electromagnetic spectrum), it allowed a number of incompatible standards to coexist for PCS service. This led directly to a weakening of competition and higher prices, as wireless PCS consumers have to buy a new appliance to migrate across providers and are unable to set up service with more than one provider using the same appliance.

\section{References}

Crandall, Robert W. 1991. After the Breakup: U.S. Telecommunications in a More Competitive Era. Washington, D.C.: Brookings Institution.

Economides, Nicholas. 1991. "Compatibility and the Creation of Shared Networks." In Electronic Services Networks: A Business and Public Policy Challenge, edited by Margaret Guerin-Calvert and Steven Wildman. New York: Praeger.

_ 1996. "The Economics of Networks." International Journal of Industrial Organization 14(2): 675-99. Also available at: http://www.stern.nyu.edu/networks/ 94-24.pdf (accessed November 19, 2004).

- 1998. "The Incentive for Non-Price Discrimination by an Input Monopolist.". International Journal of Industrial Organization 16(3): 271-84. Also available at: www.stern.nyu.edu/networks/1136.pdf (accessed November 19, 2004).

- 1999. "The Telecommunications Act of 1996 and Its Impact." Japan and the World Economy 11(3): 455-83.

2003. "The Tragic Inefficiency of M-ECPR." In Down to the Wire: Studies in the Diffusion and Regulation of Telecommunications Technologies, edited by A. Shampine. New York: Nova Science Publishers, Inc. Also available at: http:// www.stern.nyu.edu/networks/tragic.pdf (accessed November 19, 2004).

Economides, Nicholas, Giuseppe Lopomo and Glenn Woroch. 1996. "Regulatory Pricing Policies to Neutralize Network Dominance." Industrial and Corporate Change 5(4): 1013-28. Also available at: http://www.stern.nyu.edu/networks/ 96-14.pdf (accessed November 19, 2004).

Economides, Nicholas, and Lawrence J. White. 1995. "Access and Interconnection Pricing: How Efficient is the Efficient Component Pricing Rule?" The Antitrust 
Bulletin XL(3): 557-79. Also available at http://www.stern.nyu.edu/networks/ 95-04.pdf (accessed November 19, 2004).

Faulhaber, Gerald. 2004. "Bottlenecks and Bandwagons: Access Policy in the New Telecommunications." In Handbook of Telecommunications, edited by Martin E. Cave, Sumit K. Majumdar, and Ingo Vogelsang. Amsterdam: Elsevier Publishers. Federal Communications Commission. 1995. "In the Matter of Motion of AT\&T Corp. to be Reclassified as a Non-Dominant Carrier." CC Docket 95-427. Order (adopted October 12). Washington: FCC. Available at: www.fcc.gov/Bureaus/ Common_Carrier/Orders/1996/fcc96454.wp (accessed November 19, 2004).

- 1996. "First Report and Order." CC Docket N. 96-98, CC Docket No. 95185. Report (adopted August 8, 1996). Washington: FCC. 2003a. "Local Telephone Competition: Status as of June 30, 2003." Report (December 22). Washington: FCC Wireline Competition Bureau.

- . 2003b. "Report and Order On Remand And Further Notice Of Proposed Rulemaking." CC Docket 01-338, 96-98, 98-147. Report (adopted February 20; released August 21). Washington: FCC.

—. 2003c. "Trends in Telephone Service." Report (August 7). Washington: FCC Wireline Competition Bureau. Available at: http://www.fcc.gov/Bureaus/ Common_Carrier/Reports/FCC-State_Link/AAD/trend803.pdf (accessed November 19, 2004).

Gabel, David, and David F. Weiman. 1998. "Historical Perspectives on Interconnection Between Competing Local Operating Companies: The United States, 1894-1914." In Opening Networks to Competition: The Regulation and Pricing of Access, edited by David Gabel and David F. Weiman. Norwell, Mass.: Kluwer Academic Press.

Garcia-Murillo, Martha. 2003. "Assessing the Impact of Internet Telephony on the Deployment of Telecommunications Infrastructure." Working Paper 03-04. New York: Networks, Electronic Commerce, and Telecommunications (NET) Institute. Also available at: www.netinst.org/Garcia.pdf (accessed November 19, 2004).

Gregg, Billy Jack. 2001. "A Survey Of Unbundled Network Element Prices In The United States." Columbus: Ohio State University. Available at: http://www.nrri. ohio-state.edu/documents/intro0703_000.pdf (accessed November 19, 2004).

Hubbard, R. Glenn, and William H. Lehr. 1998. "Improving Local Exchange Competition: Regulatory Crossroads." Mimeo (February). New York: Columbia University. Noll, Roger G., and Bruce Owen. 1989. "The Anti-competitive Uses of Regulation: United States v. AT\&T." In The Antitrust Revolution, edited by John E. Kwoka and Lawrence J. White. New York: HarperCollins.

Weiman, David F., and Richard C. Levin. 1994. "Preying for Monopoly? The Case of Southern Bell Telephone Company, 1894-1912." Journal of Political Economy 102(1): 103-26. 